\title{
Wer Bürokratie abbauen will, muss richtig dicke Bretter bohren
}

\section{Niedersachsens KV-Vize, Hausarzt Dr. Jörg Berling, will den Bürokratieabbau zur Chefsache machen. Immerhin hatte er schon vor seiner Wahl vehement den Bürokratieabbau in den Vertragsarztpraxen gefordert. Jetzt spürt er die Mühen der Ebene.}

— Die KV Niedersachsen will mit einem Vier-Punkte-Katalog den Vertragsärzten pro Monat um etwa 48 „Bürokratiestunden“ ersparen. Konkret fordert KV-Vize Dr. Jörg Berling, erstens den Wegfall des Einzugs und der Buchung der Praxisgebühr durch die Arztpraxis. Zweitens plädiert er für den Stopp von Auskünften, Bescheinigungen, Zeugnissen, Berichten und Gutachten, die über ein einfaches Auskunftsbegehren von Anfragenden auf vereinbarten Vordrucken hinausgehen.

Drittens fordert er die Abschaffung überflüssiger Formulare und viertens die Einführung von quartalsübergreifenden Langzeitverordnungen von Arzneimitteln für chronisch kranke Patienten, die stabil eingestellt sind.

\section{Beispiele überbordender Bürokratie sind Legion}

Fachliche Qualifikation nachweisen, genehmigungspflichtige Leistungen beantragen, die Praxisgebühr einziehen, Versicherte in DMP einschreiben, Anfragen von Krankenkassen beantworten - die Beispiele überbordender Bürokratie sind Legion, klagt Berling. „Warum etwa brauche ich für Privatpatienten nur ein blaues Rezept, während ich für GKVPatienten zwei verschiedene Rezepte für Ergo- und Physiotherapie benötige?"

„Was soll der Unsinn eines Antrages, mit dem der Patient zu seiner Krankenkasse gehen muss, um einen weiteren Antrag entweder auf Kostenübernahme durch die Rentenversicherung oder die
Kasse zu erhalten, den ich als Hausarzt dann ausfüllen muss?“

\section{Streit um BTM-Rezepte}

Derzeit streitet die KV mit verschiedenen Betriebskrankenkassen darüber, wie BTM-Rezepte ausgefüllt werden müssen. In letzter Zeit haben Betriebskassen vermehrt Apotheken Geld ver-

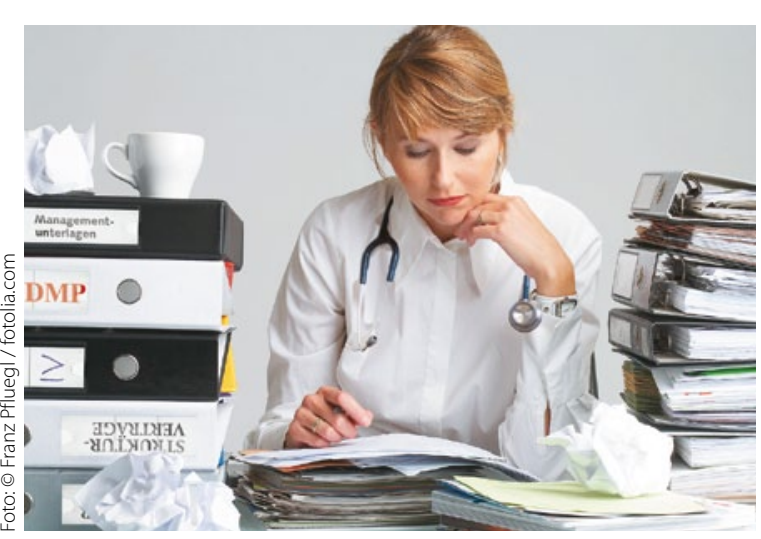

Von der Wiege bis zur Bahre: Formulare, Formulare ...

weigert, etwa weil die Rezepte durch ein Namenskürzel oder nicht erkennbar mit der ganzen Unterschrift des Arztes gezeichnet waren.

Derart wuchernde Kontrollbürokratie erwachse aus einer „Misstrauenskultur“, so Berling. Allein in der KV Niedersachsen hätten die Ärzte im Jahr etwa 280 Informationspflichten gegenüber Kassen, KV und Behörden.

Dieser bürokratische Aufwand resultierte aus 65 verschiedenen Gesetzen, Verordnungen, Richtlinien und Verein- barungen, hat Berling ermittelt. „Das müssen wir entschlacken!“

\section{Dokumentation kostet auch richtig viel Geld}

Die KV Westfalen Lippe (KVWL) habe errechnet, was das Ganze kostet, sagte Berling: „Die Dokumentationspflichten der Vertragsärzte der KVWL verschlang allein im Jahr 2006 rund 160 Millionen Euro."

Berling ist in der Pflicht, hat er doch vor seiner Wahl als harscher Kritiker die bürokratischen Extratouren im Gesundheitssystem angeprangert und auch von der KV rasches Handeln gefordert. Nun sitzt er selber im Vorstand und will liefern und er stößt überall auf dicke Bretter.

„Wir brauchen Allianzen der Landes-KVen, wir müssen immer wieder Politik- und Kassenvertreter ansprechen, und wir müssen Öffentlichkeit herstellen“, erklärt Berling.

„Bei der KBV habe ich erfahren, dass man offenbar eine Modellregion einrichten will, in der Bürokratieabbau erprobt werden soll“, berichtet Berling, „aber das kann es ja nicht sein. Jetzt muss schnell und konkret gehandelt werden."

Das kann allerdings dauern. Die KBV gab sich auf Anfrage jedenfalls zugeknöpft. Eine KBV-Sprecherin wollte nicht einmal das Wort "Modellregion“ in den Mund nehmen: „Derzeit können und wollen wir zu all dem nichts sagen.“ 